\title{
Relationship Between Jump Performance and Sport Ages in U16 Basketball Players
}

\author{
Ozlem Orhan ${ }^{1}$, Sezen Cimen Polat ${ }^{1} \&$ Imdat $_{\text {Yarim }}{ }^{1}$ \\ ${ }^{1}$ Gazi University Faculty of Physical Education and Sports, Turkey \\ Correspondence: Sezen Cimen Polat, Gazi University College of Physical Education and Sports, Gazi Mahallesi \\ Abant Sokak No:12 Ankara, Turkey. E-mail: sezencimen@gazi.edu.tr
}

Received: January 22, 2019

Accepted: February 20, 2019 Online Published: March 6, 2019

doi:10.5539/jel.v8n2p207

URL: https://doi.org/10.5539/jel.v8n2p207

\begin{abstract}
This study was conducted to evaluate the jump performance of youth basketball players according to their sport ages. 26 male basketball players (14.1 \pm 1.6 year) who participated in the study were divided into two groups of sport ages of 4 and below $(\leq 4)$ and 6 and above $(\geq 6)$. The group with sports ages $\leq 4$ consisted of 12 male basketball players with a height of $162 \pm 2.56 \mathrm{~cm}$, a body weight of $51.4 \pm 3.04 \mathrm{~kg}$, a body mass index of $19.4 \pm 0.74 \mathrm{~kg} / \mathrm{m}^{2}$. The other group with sports ages $\geq 6$ consisted of 14 male basketball players with a height of $155.9 \pm 1.98 \mathrm{~cm}$, a body weight of $45.7 \pm 1.85 \mathrm{~kg}$, a body mass index of $18.8 \pm 0.69 \mathrm{~kg} / \mathrm{m}$. All basketball players' squat jump (SJ) and countermovement jump (CMJ) were measured (Optojump Microgate Bolzano, Italy). The Mann Whitney $\mathrm{U}$ test was used to determine whether there were differences between groups in terms of $\mathrm{T}$ flighttimes and jump heights. Statistically significant level of $\mathrm{p}<0.05$ was accepted. As a result of the study, no statistically significant difference was observed between the sport ages and SJ and CMJ splashes. In this respect, it can be considered that the Jump performance does not develop in parallel with the training age, and that the jump ability of this cause may be more related to motor skill and ability than the training age.
\end{abstract}

Keywords: basketball, counter movement jump, squat jump, sport ages

\section{Introduction}

Basketball is a branch of sports that motoric features such as durability, strength, speed, skills, and mobility are important (Tusunawake et al., 2003). In addition to technical, tactical, and psychological skills, performance in basketball also depends on anthropometric properties and physical fitness levels (jumping, agility with and without the ball, and speed of cyclic or acyclic movements) (Apostolidis et al., 2004; Delextrat \& Cohen, 2009). Jumping is an important motor parameter that requires a high degree of coordination, which is providing motor coordination between the upper and lower body (David et al., 2017). In the studies conducted, it was stated that the jumping was one of the basic parameters for performance in football (Stolen et al., 2005), basketball (Ziy \& Lidor, 2009), volleyball (Sheppard et al., 2008), and handball (Kruger et al., 2014).

Multiple jump testing, countermovement jump test, and squat jump test are used to determine jumping performance (Sands et al., 2004; Orhan et al., 2015). These tests are tests that utilize the jump height to measure the quick power indirectly. The explosive power, starting power, and elastic power, which are known as the jumping power, are the sub-branches of the quick power and are directly influenced by the maximal force. If only the effect of the contractible component is to be measured, the squat jump (SJ) test is used, while if the effect of both the contractible and the viscoelastic component is to be measured, then, the countermovement jump (CMJ) test is applied (Potteiger et al., 2010).

Training methods that accelerate the muscle response of the vertical jump and leg strength are emphasized a lot, especially by the basketball trainers. In basketball, the success of coordinated movements in a regular way and the conversion of them into skills is the result of very good developed motoric features. Basketball sport has a structure that includes movements such as acceleration and deceleration as well as skills such as direction changes and jumps. Especially the jumping power, arm power (shooting and passing), and sprint power development are prominent among them (Maggioni et al., 2018).

In addition to all these features, it is stated that age and maturity are important characteristics of performance. The maturation differences between individuals of the same age can affect their performances (Torres-Unda et 
al., 2017). Gall et al. found in their study on football players in the 14-17 age group that height and weight parameters and also speed and Vo2max performance factors, as well as the age of training, can cause changes in performance (Gall et al., 2010).

Apart from the training age, talent selection is also a very important criterion in terms of performance in basketball. The performance requirements during the game allow the talent to come to the fore from time to time. The skills such as jumping, speed, etc., are included in the class of skills that are difficult to develop by training. In a study, it was examined whether the age of training and the success of the footballers were related to their anaerobic capacity or not and no correlation was found between the training age and anaerobic performance (Torres-Unda et al., 2017).

Basketball can be evaluated among the sports branches where the talent selection is evaluated as a priority and the training process is progressed very systematically. While the contents and intensity of the trainings are very important in terms of the success of the teams, talented players may come to the fore in the team sometimes. In this study, the relationship between the training age and the jumping skill that is considered as an important skill for scoring in the basketball game is investigated.

Due to the lack of studies on the age of training, which is one of the important parameters of performance in basketball, and to examine the relationship between age that is an important parameter in performance and jumping performance this study has been conducted.

\section{Methods}

\subsection{Participants and Measurements}

26 male basketball players aged 14.1 \pm 1.6 years participated in the study. Basketball players were divided into two groups as sports ages of under $4(\leq 4)$ and over $6(\geq 6)$. They were engaged in formal training and competition for at least 4-6 years. Participants were informed about the nature of the study and were also informed that participation was voluntary and that they could withdraw at any time. Players and their parents or legal guardians provided informed written consent. The nature of the study and any possible risks associated with participation were explained to the youth and parents in compliance with the Declaration of Helsinki. The height measurements of subjects were measured with Holtain Limited height measurement device while they were resting with bare feet (Sensibility $0.01 \mathrm{~m})$. On the other hand, body weights just with short and t-short were weighed with Angel electronic weighting machine (Sensibility $0.01 \mathrm{~kg}$ ).

Their squat jump (SJ) and countermovement jump (CJ) values were also measured (Optojump Microgate Bolzano, Italy). After a full explanation of experimental procedures, subjects completed a standardized warm-up consisting of treadmill running at 6-10 kilometers per hour (5 minutes) and stretching of lower extremity muscles. The following jump modalities were considered: SJ and CMJ with 3 repetitions per modality. For SJ, subjects started from the upright standing position with their hands on their hips, they were then instructed to flex their knees and hold a predetermined knee position (approximately $90^{\circ}$ ), and the experimenter then counted out for 3 seconds. On the count of 3 , the subject was instructed to jump as high as possible without performing any countermovement before the execution of the jump. For CMJ, subjects started from the upright standing position with their hands on their hips (i.e., without arm swing); they were then instructed to flex their knees (approximately $90^{\circ}$ ) as quick as possible and then jump as high as possible in the ensuing concentric phase. For CMJ, subjects were instructed to perform a CMJ with arm swing during the execution of the jump (i.e., hands were free to move). With all jumps, it was recommended that at takeoff the subjects leave the floor with the knees and ankles extended and land in a similarly extended position. A rest interval of 30 seconds was interspersed between jump repetitions, while 2 minutes was allowed between jump series. The Optojump system measured the flight time of vertical jumps with an accuracy of 1/1000 seconds (1 kHz). Jump height was then estimated as 9.81X flight time ${ }^{2} / 8(3)$. Each test was repeated twice and the highest value was recorded in $\mathrm{cm}$.

\subsection{Statistical Analysis}

Average and standard deviation values have been interpreted as the definitive statistics. All the meaningfulness degrees have been determined at $p<0.05$ level. Mann Whitney $U$ test was applied to determine if there was any difference between the groups in T flight and jump heights. Statistical significance was accepted as $p<0.05$. 


\section{Results}

The ages of the participants were $14.1 \pm 1.6$ years. Table 1 shows the height, body weight and body mass index (BMI) values of the subjects according to their sport ages (4 years and less, 6 and more). Table 2 presents SJ Tflight (sec), SJ height (cm), CMJ T flight (sec), and CMJ height (cm) values.

Table 1. Height, body weight, and body mass index mean values

\begin{tabular}{llll}
\hline Parameters $(\mathrm{n}=26)$ & Sport ages (year) & Mean \pm SS & $\mathrm{p}$ \\
\hline Height $(\mathrm{cm})$ & $4<(\mathrm{n}: 12)$ & $162 \pm 2.56$ & 0.09 \\
& $6>(\mathrm{n}: 14)$ & $155.9 \pm 1.98$ & \\
Weight $(\mathrm{kg})$ & $4<$ & $51.4 \pm 3.04$ & 0.24 \\
& $6>$ & $45.7 \pm 1.85$ & \\
BMI $(\mathrm{kg})$ & $4<$ & $19.4 \pm 0.74$ & 0.44 \\
& $6>$ & $18.8 \pm 0.69$ & \\
\hline
\end{tabular}

Note. $\mathrm{p}<0.05$.

Table 2. Comparison of SJ and CMJ jumping performances according to sports age

\begin{tabular}{llll}
\hline Parameters $(\mathrm{n}=26)$ & Sport ages (year) & Mean \pm SS & $\mathrm{p}$ \\
\hline SJ T flight $(\mathrm{sn})$ & $4<(\mathrm{n}: 12)$ & $0.43 \pm 0.01$ & 0.86 \\
& $6>(\mathrm{n}: 14)$ & $0.43 \pm 0.01$ & \\
SJ height $(\mathrm{cm})$ & $4<$ & $22.6 \pm 1.32$ & 0.86 \\
& $6>$ & $22.7 \pm 1.01$ & \\
CMJ T flight(sn) & $4<$ & $0.44 \pm 0.01$ & 0.96 \\
& $6>$ & $0.43 \pm 0.01$ & \\
CMJ jump height $(\mathrm{cm})$ & $4<$ & $24.1 \pm 1.29$ & 0.61 \\
& $6>$ & $22.6 \pm 1.03$ & \\
\hline
\end{tabular}

Note. $\mathrm{p}<0.05$.

\section{Discussion}

This study was carried out to evaluate the sport ages and jump performance of basketball players. It was found that the jump performance and the sport ages of the basketball players did not improve in parallel. It is known that performance is influenced by factors such as age, sex, the age of training, and level of trainability (Bompa, 1991). Training age is an important parameter, especially for performance athletes. However, according to the results of the study, it can be said that only the age of the training is not an effective parameter in evaluating the performance. It is stated that there may be some performances in which anthropometric criteria and talent factor, as well as the age of training, are effective. The growth process involves individual-specific differences. Different maturation levels can be seen in the same chronological age. In other words, individual maturation is explained by biological maturation (Baxter-Jones, 1995). Different maturity levels in the same chronological age are closely related to biomotor and sportive performance (Carlos et al., 2012). Body composition and performance differences related to maturity in adolescence vary according to early and late maturation (Valente et al., 2012; Carlos et al., 2012). In a study conducted with 42 Brazilian football players aged between 11-15 years, Gobbi and colleagues investigated the effect of biological maturation on sprint and agility performance. As a result of their study, it was determined that biological maturation had a significant effect on sprint and agility performance. In addition, they stated that the training history was not effective on sprint and agility performance alone (Gobbi et al., 2010).

In basketball, sudden acceleration, change of direction, sudden stop, jump, and shooting skills shown during the game are important criteria in terms of game performance and scoring. Although jumping is important for all kinds of sportive activities, it becomes more important in some sports such as basketball in which anaerobic power is used massively. Jumping plays an important role in both defensive and offensive maneuvers in training and matches in basketball (Ziy \& Lidor, 2010; Ignacio et al., 2017). To evaluate the lower extremity strength, squat jump and active jump tests are frequently preferred field tests (Cardinale et al., 2011). In the majority of studies, it is seen that the relationship between SJ height and CMJ and sprint performance is examined (Shalfawi et al., 2014). Moreover, it is seen that with the SJ and CMJ tests, the relations between motoric parameters such as direction change abilities, agility, and power are examined (Comfort et al., 2014; Meylan et al., 2009). In a study conducted by Chaouachi et al., which they examined the relationship between 1 repetitive maximum 
(RM)-SJ and agility in elite men's basketball players, they reported that SJ exercises should be a component of basketball training when they considered the relationship between $1 \mathrm{RM}-\mathrm{SJ}$ and short-term sprints (Chaouachi et al., 2009). Rodriguez and friends could not find a relationship between the age and vertical jumps of basketball players in their research conducted with U15 basketball players (David et al., 2017).

When the studies on age and performance are examined, it is seen that there are studies that discuss their effects especially in team sports (Baker et al., 2012; Till et al., 2010; Ford \& Williams, 2011). In team sports, physiological, psychological, motoric, and conditional features, as well as technical and tactical elements have an important place in performance (Ford \& Williams, 2011). Therefore, it is thought that evaluating motoric abilities as a whole together with age will give a more effective perspective in terms of performance.

As a result, while it is clearly seen in many studies that age and performance development can be quite important in the training process and periodization in team sports, when it is evaluated in terms of game performance, sometimes individual talents stand out regardless of age parameters of the players in the team. To sum up, according to the findings, no relation was found between jumping performance and targeted age group. It can be said that the training age does not show a significant effect when evaluated in terms of an anaerobic performance such as jumping. Consequently, relationship between sport age and jump performance would not develop the same direction in adolescent ages.

\section{References}

Adams, G. M. (1998). Exercise physiology laboratory manual (3rd ed.). Boston, MA: McGraw-Hill.

Apostolidis, N., Nassis, G. P., Bolatoglou, T., \& Geladas, N. D. (2004). Physiological and technical characteristics of elite young basketball players. Journal of Sports Medicine and Physical Fitness, 44(2), 157-163.

Ateş, B., \& Çetin E. (2017). Influence of vertical jump performance on acceleration maximal speed and change of direction speed in professional soccer players. International Journal of Advenced Research, 5(12), 13661371. https://doi.org/10.21474/IJAR01/6095

Baker, J., Janning, C., Wong, H., Cobley, S., \& Schorer, J. (2012). Variations in relative age effects in individual sports: Skiing, figure skating and gymnastics. European Journal of Sport Science, 14(1), 183-190. https://doi.org/10.1080/17461391.2012.671369

Baxter-Jones, A. D. G. (1995). Growth and development of young athletes. Should competition levels be age related? Journal of Sports Medicine, 20(2), 59-64. https://doi.org/10.2165/00007256-199520020-00001

Bompa, T. O. (2009). Theory and methodology of training (2nd ed.). Dubuqu e, IA: Kendall/Hunt

Cardinale, M., Newton, R., \& Kazunori, N. (2011). Speed and agility assessment (pp. 259-277). In Strength and Conditioning: Biological principles and practical applications; Wiley-Blackwell: West Sussex, UK.

Carlos, E. B., Gonçalves, L., Rama, M. L., \& Figueiredo, A. B. (2012). Talent identification and specialization in sport: an overview of some unanswered questions. International Journal of Sports Physiology and Performance, 7(4), 390-393. https://doi.org/10.1123/ijspp.7.4.390

Chaouachi, A., Brughelli, M., Chamari, K., Levin, G. T., Ben, A. N., Laurencelle, L., \& Castagna C. (2009). Lower limb maximal dynamic strength and agility determinants in elite basketball players. Journal of Strength and Conditioning Research, 23(5), 1570-1577. https://doi.org/10.1519/JSC.0b013e3181a4e7f0

Comfort, P., Stewart, A., Bloom, L., \& Clarkson, B. (2014). Relationships between strength, sprint, and jump performance in well-trained youth soccer players. Journal Strength and Conditioning Research, 28(1),173177. https://doi.org/10.1519/JSC.0b013e318291b8c7

David, R. G. R., Ricardo M. C., Felıpe F. M., Rquez, J. M., Juan, J., \& Gonza, L. B. (2017). Traditional vs. sport-specific vertical jump tests: reliability, validity, and relationshıp with the legs' strength and sprint performance in adult and teen soccer and basketball players. Journal of Strength and Conditioning Research, 31(1), 196-206. https://doi.org/10.1519/JSC.0000000000001476

Delextrat, A., \& Cohen, D. (2009). Strength, power, speed, and agility on women basketball players according to playing position. Journal of Strength and Conditioning Research, 23(7), 1974-1981. https://doi.org/10.1519/JSC.0b013e3181b86a7e

Ford, P. R., \& Williams, M. A. (2011). No relative age effect in the birth dates of award-winning athletes in male professional team sports. Research Quarterly for Exercise and Sport, 82(3), 570-573. https://doi.org/10.1080/02701367.2011.10599790 
Gobbi, B., Kokubun E., Teresa, L., Pauli, R. J., Barbieri, A. F., \& Pittoli, M. E. T. (2010). Brazillian soccer players and nonplayers adolescents: Effect of the maturity status on the physical capacity components performance. Journal of Human Sport and Exercise, 5(2), 280-287. https://doi.org/10.4100/jhse

Hara, M., Shibayama, A., Arakawa, H., \& Fukashiro, S. (2008). Effect of arm swing direction on forward and backward jump performance. Journal of Biomechanics, 41(13), 2806-2815. https://doi.org/10.1016/j.jbiomech.2008.07.002

Ignacı, P.-M., Rodrigo, R.-C., Jarro A.-G., Cristıan A., Abbas, A., Jason, M., \& Helmı, C. (2006). Effects of progressed and nonprogressed volume-based overload plyometric training on components of physical fitness and body composition variables in youth male basketball players. Journal of Strength and Conditioning Research, 1-8.

Kruger, K., Pilat, C., Uckert, K., Frech, T., \& Mooren, F. C. (2014). Physical performance profile of handball players is related to playing position and playing class. Journal Strength and Conditioning Research, 28(1), 117-125. https://doi.org/10.1519/JSC.0b013e318291b713

Le, Gall, F., Carling, C., Williams., M., \& Reilly, T. (2010). Anthropometric and fitness characteristics of international, professional and amateur male graduate soccer players from an elite youth academy. Journal of Science and Medicine in Sport, 13(1), 90-95. https://doi.org/10.1016/j.jsams.2008.07.004

Maggioni, M. A., Bonato, M., Stahn, A., La Torre, A., Agnello, L., Vernillo, G., Castagna, C., \& Merati, G. (2018). Effects of ball-drills and repeated sprint ability training in basketball players. International Journal of Sports Physiology and Performance, 20, 1-24. https://doi.org/10.1123/ijspp.2018-0433

McFarland, I. T., Dawes J. J., Elder, C. L., \& Lockie, G. R. (2016). Relationship of two vertical jumping tests to sprint and change of direction speed among male and female collegiate soccer players. Sports, 4(1), 1-7. https://doi.org/10.3390/sports4010011

Meylan, C., McMaster, T., Cronin, J., Mohammad, N. I., Rogers, C., \& Deklerk, M. (2009). Single-leg lateral, horizontal, and vertical jump assessment: Reliability, interrelationships, and ability to predict sprint and change-of-direction performance. Journal of Strength and Conditioning Research, 23(4), 1140-1147. https://doi.org/10.1519/JSC.0b013e318190f9c2

Orhan, Ö., Yarım, İ., Bilgin, U., \& Çetin E., (2015). Yüksek irtifanın farklı sıçrama performansları üzerine etkilerinin incelenmesi. Spormetre, 13(1), 11-15.

Potteiger, J. A., Smith, D. L., Maier, M. L., \& Foster T. S. (2010): Relationship between body composition, leg strength, anaerobic power, and on-ice skating performance in division I men's hockey athlete. Journal of Strength and Conditioning Research, 24, 1755-1762. https://doi.org/10.1519/JSC.0b013e3181e06cfb

Sands, W. A, McNeal, J. R, Ochi, M. T., Urbanek, T. L., Jemni, M., \& Stone, M. H. (2004). Comparison of the wingate and bosco anaerobic test. Journal of Strenght and Conditioning, 18(4), 810-814.

Shalfawi, S., Enoksen, E., \& Tonnessen, E. (2014). The relationship between measures of sprinting, aerobic fitness, and lower body strength and power in well trained female soccer players. Interantional Journal of Applied Sports Sciences, 26(1), 18-25.

Sheppard, J. M., Cronin, J. B., Gabbett, T. J., McGuigan, M. R., Etxebarria, N., \& Newton, R. U. (2008). Relative importance of strength, power, and anthropometric measures to jump performance of elite volleyball players. Journal of Strength and Conditioning Research, 22(3), 758-765. https://doi.org/10.1519/JSC.0b013e31816a8440

Stolen, T., Chamari, K., Castagna, C., \& Wisloff, U. (2005). Physiology of soccer: An update. Sports Medicine, 35(6), 501-536. https://doi.org/10.2165/00007256-200535060-00004

Till, K., Cobley, S., Wattie, N., O’Hara, J., Cooke, C., \& Chapman, C. (2010). The prevalence, influential factors and mechanisms of relative age effects in UK rugby league. Scandinavian Journal of Medicine and Science in Sports, 20, 320-329. https://doi.org/10.1111/j.1600-0838.2009.00884.x

Torres-Unda, J., Zarrazquin, I., Gravına, L., Zubero, J., Seco, J. S., Susana, M., Gıl, J., \& Irazusta J. (2017). Basketball performance is related to maturity and relative age in elite adolescent players. Journal of Strength and Conditioning Research, 30(5), 1325-1332. https://doi.org/10.1519/JSC.0000000000001224

Tusunawake, N., Tahara, Y., \& Moji, K. (2003). Body composition and physical fitness of female volleyball and basketball players of the japan interhigh school championship teams. Journal of Physiological Antropology and Applied Human Science, 22(4), 195-201. https://doi.org/10.2114/jpa.22.195 
Valente-dos-Santos, J., Coelho-e-Silva, M. J., Martins, R. A., Figueiredo, A. J., Cyrino, E. S., Sherar L. B., Vaeyens, R., Hujisen, B. C. H., Elferink-Gemser, M. T., \& Malina, R. M. (2012). Modelling Developmental changes in repeated-sprint abilityby chronological and skeletal ages in young soccer players. International Journal of Sports Medicine, 33, 773-780.

Wisloff, U., Castagna, C., Helgerud, J., Jones, R., \& Hoff, J. (2004). Strong correlation of maximal squat strength with sprint performance and vertical jump height in elite soccer players. British Journal of Sports Medicine, 3883, 285-288. https://doi.org/10.1136/bjsm.2002.002071

Ziv, G., \& Lidor, R. (2010). Vertical jump in female and male basketball players: A review of observational and experimental studies. Journal of Sciences and Medicine in Sport, 13(3), 332-339. https://doi.org/10.1016/j.jsams.2009.02.009

Ziv, G., \& Lidor, R. (2009). Physical attributes, physiological characteristics, on-court performances and nutritional strategies of female and male basketball players. Sports Medicine, 39(7), 547-568. https://doi.org/10.2165/00007256-200939070-00003

\section{Copyrights}

Copyright for this article is retained by the author, with first publication rights granted to the journal.

This is an open-access article distributed under the terms and conditions of the Creative Commons Attribution license (http://creativecommons.org/licenses/by/4.0/). 